distilled water, and on examination were found to contain a spirillum exactly like the fine form found in the sore. Other cases were taken and we have now observed the same organism in three patients. Films were taken from spots on the abdomen, chest, and arm. The spirilla do not occur in large numbers and often require a long search and in some of the films only one has been seen. In one patient the organism was seen in a blood film taken on each of ten successive days and in the three cases in which the organism was found in the blood it had previously been seen in all forms in the primary lesion.

From our observations the presence of spirochætæ in the venereal sore appears to be diagnostic of syphilis, and up to the present all cases in which the organism has been found have developed a secondary rash. Later we hope to publish statistics of a large number of cases.

Royal Naval Barracks, Portsmouth.

\section{SECONDARY EFFECTS UPON THE SYSTEM WHICH MAY BE PRODUCED BY CHRONIC ENLARGEMENT OF THE TONSILS.}

\section{BY H. BELLAMY GARDNER, M.R.C.S. ENG.,} L.R.C.P. LOND.

THE study and practice of anæesthetic administration direct the attention of the anæsthetist primarily to the condition of the respiratory system and teach him to observe intimately those effects which are produced by even the slightest interference with efficient oxidation of the blood. In this way the induction of anæsthesia becomes instinctively to the anæsthetist the application of a test of the integrity of the patient's respiratory apparatus and of the vitality of the respiratory centre in the medulla. Secondarily the tone of the vaso-motor mechanism and strength of the circulation are elicited, whilst during successive stages symptoms which may be due to particular nervous states, derangements, or diseases become evident to him through his constant experience of the behaviour of the human organism under this test.

I do not intend in the present article to enter further into the interesting points which these facts disclose than is necessary to draw attention to the probability of the view that chronic obstruction to respiration, even if it be purely mechanical and situated in the upper air passages, may produce a certain degree of those effects which are commonly attributed only to obstructive lung and heart diseases. Increased systemic intravenous pressure is obviously a contributing factor in the causation of varicose veins of the legs and is so classified in the surgical text-books. It is further admitted that this increased intravenous pressure may be produced by mitral valvular incompetence, chronic bronchitis, emphysema, or the pressure of a growth or aneurysm within the chest. The effects upon the circulation which we are considering when produced by such causes are identical-namely, a retardation of the venous circulation with consequent engorgement of the systemic veins and limitation of the oxidation processes in the lungs-a condition which might be generally described as one degree of chronic asphyxia.

Now, for the sake of illustration, let us take the case of a man suffering from chronic emphysema and varicose veins when the latter require operation. If a closed method of anæsthetic administration be adopted in such a case by means of ether with a bag inhaler extremely laboured breathing and cyanosis with much secretion of mucus will ensue, a condition which might generally be described as exhibiting two degrees of asphyxia. This condition is the result of (1) the patient's chronic state of one degree of asphyxia due to emphysema; and (2) moderate air limitation by re-breathing at intervals into a closed bag. This is, of course, a bad method of anæsthetising such subjects but is given to illustrate the argument.

During ten years' work at one of the London general hospitals I have found that there is a particular type of youth who requires treatment for varicose veins and in whom no obvious cause as given by the text-books can be found for their appearance in the patient's history, occupation, or physique. The type mentioned is usually a male about 20 years of age, thick-set, of middle height, and somewhat powerful build; he is florid in complexion and fullthroated. Many of these have been desirous of entering the army but have been refused solely on account of varix, being deemed otherwise to be healthy lads. Now if ether be administered to such a patient by means of a closed method or bag inhaler, even when the mouth has been propped open, extremely laboured breathing, cyanosis, and excessive secretion of mucus will ensue, a condition I have described above as presenting two degrees of asphyxia. These results do not follow the administration of ether by this method to a patient without some existing asphyxial factor within the system. If the throat be examined in this particular type of youth considerable chronic enlargement of both tonsils or of one tonsil will be found which partly blocks the air way and in many cases reduces it to about half its proper size. My belief is that the chronic obstruction to free respiration and oxidation of the blood from which these patients suffer produces a certain degree of chronic engorgement throughout the systemic veins and that this factor-that is, the enlarged tonsils-contributes to the gradual dilatation of the veins in the legs for which they come under treatment. I need hardly mention that a more open method and some other anæsthetic are more suitable for such cases in order to secure tranquil and non-asphyxial anæsthesia.

In my experience there are also large numbers of cases in childhood and youth which present themselves for the treatment of hernia and at the same time labour under this form of obstructed respiration. It is evident that the chief exciting cause of hernia must be increase in the intraabdominal pressure, for it is within the experience of every practitioner of medicine that hernia has made its first appearance after whooping-cough and bronchitis. Powerful contractions of the abdominal wall are observed during cough and laboured breathing-and the latter is obvious when a child with enlarged tonsils falls asleep in the supine position. In fact, so conscious do these patients become of their discomfort that it will be observed that they prefer to lie prone upon their faces in bed with the forehead upon the pillow or head to one side, and the mouth open in order that the tonsils should hang forward and free the air way. When such a patient is anæsthetised even with chloroform and no asphyxial factor is present excepting the tonsils laboured breathing, jerky movements of the abdominal wall, and occasional tendency to coughing appear, unless the mouth be opened and the lower jaw held forward to remove the tonsils from contact with the pharynx. I have frequently administered anæsthetics for the radical cure of hernia where enlargement of the tonsils has been considerable and have as constantly observed the same patients asleep in the hospital ward during their convalescence a week or more afterwards, snoring deeply, with exaggerated jerky abdominal movements going on, proving to me only too clearly how the hernia had been forced down by the continuous action of obstructed respiration.

I am well aware that the predisposing causes may be considered more potent factors in both these diseases; all I desire is that, considering the simplicity of the operation for excising the tonsils, this exciting cause of increased intravenous and intra-abdominal pressure should be recognised and removed both as a preventive measure and also before radical treatment for its secondary effects is carried out.

Mansfield-street, $\mathbf{W}$.

\section{Clinical 算lotes:}

\section{MEDICAL, SURGICAL, OBSTETRICAL, AND} THERAPEUTICAL.

\section{A CASE OF ACUTE POISONING BY EUCALYPTUS OIL.}

By Henry S. TAYLOR, M.D. ABERD.

As cases of poisoning by eucalyptus oil are very uncommon and are not even mentioned in the editions $I$ have by me of either "Taylor's Medical Jurisprudence" by Stevenson, or "Murrell on Poisons," a record of a case which I attended some time ago may be of interest, perhaps more espe. cially so as eucalyptus oil is regarded by the general public 
and, I think, also to a great extent by the medical profession, as a more or less innocuous drug.

In the early part of 1902 I was hurriedly called one night to a patient who was said to be dying. On arrival at the house I found the patient, a strong and perfectly healthy man, about 25 years of age, in the following condition Fe was at an open window, gasping for breath, his head hanging over the window-sill; his face was intensely con. gested and then changed to a pale livid hue for an interval, after which there was a return to a deep purple. His ideas were confused, he made wandering and inconsequent remarks, and when I drew him from the open window he made persistent, though badly coördinated, efforts to return to it. He had a sense of impending suffocation, which only hasging his head out of the open window somewhat mitiated. His general movements were extremely restless, the extremities were cold and clammy, and the pulse was very slow; convulsive movements of both hands and feet occurred every now and then; his fingers were tightly clenched on his hands. He then became cemi-comatose and sank into a state of stupor, from which I had very great difficulty in rousing him, and as soon as I desisted from my efforts the stupor returned, his head sank forward, and he fell into the comatose condition again. His general condition now became alarming and all my efforts to couse him failed.

The history of the attack was as follows. He went home to supper in perfect health and made an ordinary meal with his asual appetite, carried on conversation, and generally was in his asual excellent health and condition. He was a very strict teetotaler and never took any alcohol. After supper he remarked that he had "a bit of a cold" and that he would take a "good dose of eucalyptus" on going to bed. He accordingly, by his own account, swallowed a large teaspoonful of the oil, plain, and within a few minutes of his doing so he complained of a severe smarting pain down the cophageal tract and in the gastric region, followed by the symptoms which I have detailed. His breath had a powerful odour of eucalyptus and his pupils were inclined to be contracted but only to a small extent. I gave him first stimulants, as he was very collapsed, and then a good dose of ipecacuanha and sulphate of zinc; after this he vomited freely the contents of his stomach which filled the room with the odour of the eucalyptus oil mixed with them. Soon after vomiting the symptoms began to abate, his ideas from being confused became more collected and he was able to give me a clear account of what had happened, the semicomatose state disappeared, and he gradually returned to his ordinary health and condition. The next morning he was quite well and went about his usual business.

The oil which he had taken he had purchased in the town and it was possibly not very pure or of a very good quality. I asked him whether he had often taken the oil he said, "Ob, yes, whenever I have a cold I take about 15 drops." It had never affected him when so taken, but he cemembered that on one occasion, when he had taken half a teaspoonful at a dose, he became very giddy and a little confused; these symptoms, however, did not last long or go any further; he identified the sensations he had then as being the same as the initial symptoms of the attack I have described before he became confused and lost consciousness and there is no doubt that his condition was due to an overdose of the drug.

It would be interesting if any of the readers of THE LANCET could furnish particulars of any cases which they may have met with of untoward symptoms following on taking a large dose of this oil.

kiekssburg, Orange River Colony, South Africa

\section{IWO CASES OF POISONING FROM THE APPLICATION} OF ATROPINE TO THE EYES.

By Percy B. Spurgin, L.R.C.P. Lond., M.R.C.S. EnG.

THF two following cases are of interest owing to their severity and the unusual means of poisoning; also as showing the marked idiosyncrasy which the children displayed with respect to the action of the drug.

The first patient was an excitable girl, aged ten years, who nad been attending an eye hospital for cataract and had been given for instillation "guttæ atropinæ" containing four grains of atropine in the ounce. One day in July, 1901, I was sent for urgently to see the child and found her covered with a diffuse rash closely resembling that of scarlet fever. Her temperature was $102.7^{\circ} \mathrm{F}$ and her pulse-rate was 140 Her fauces and tonsils were much inflamed; she had a typical strawberry tongue and frontal headache but there was no vomiting. Inquiry elicited the fact that an hour previously the drops had been instilled, the patient then appearing to be quite well. An aperient powder and a saline mixture were prescribed. In the evening all the symptoms had considerably abated. Next morning the rash had disappeared completely, the throat was normal, the tongue was clean, the pulse-rate was 98 , there was no headache, and the child had slept well. In two days she had recovered completely.

The second patient was a girl, aged three and a half years, who had been attending the same hospital for strabismus and had been having instillations of "guttæ atropinæ" containing two grains of atropine in the ounce. Sent for one morning I found that the child had vomited and was rather collapsed. Her temperature was $101 \cdot 3^{\circ} \mathrm{F}$. and her pulse-rate was 116. Her tongue was furred, her throat was slightly inflamed, and her chest and back and the upper part of her thighs were covered with a scarlatiniform rash. The same treatment as in the previous case was adopted with the addition of half a drachm of brandy in half an ounce of water, administered immediately, and a hot-water bottle applied to the feet. On the same evening she was better and on the next morning she was feeling quite well and all signs had disappeared.

In neither case was there subsequent desquamation. The diagnosis in both cases was poisoning by the "guttæatropinæ." Careful inquiry elicited the fact that in neither case did the "guttæ" drop or trickle into the mouth; the rapidity of absorption and the speedy appearance of symptoms-in each case under one and a quarter hours-were remarkable.

Wimbledon, s.W.

\section{A CASE OF (?) TUBERCULOUS MENINGITIS TREATED WITH IODOFORM OINTMENT.}

\section{By Hexry C. WILSON, L.R.C.P. IREL., L.F.P.S. GlasG.}

ON July 16th, 1905, I was called to see a boy of delicate aspect, aged six years. He was feverish, his temperature being $102^{\circ} \mathrm{F}$., his pulse-rate 120 , and he had been vomiting throughout the day. I gathered from the mother that during the previous week he had complained of headache, had cried if spoken to, was irritable, and not of his usual disposition. On the following morning his condition was much the same and he continued to vomit. In the evening, when I saw him again. he was in a semi-comatose condition. On the 18th the characteristics of meningitis were well developed. Retraction of the head, Kernig's sign, tache cérébrale, and twitchings of muscles were present The pupils were dilated, the face was alternately flushed and pallid, and the boy could be roused only with difficulty. An ice-bag was kept applied to the scalp. A saline mixture containing iodide and bromide of potassium and calomel in a small dose were prescribed. On the 19th he remained much the same but was weaker and more comatose. His temperature was $101^{\circ}$ and his pulse-rate was 80 . The muscles of his left leg were rigid and his condition altogether was most unfavourable. In the evening an ointment consisting of 15 grains of iodoform in an ounce of vaseline was rubbed into the scalp and the back of the neck and instructions were given that this was to be done thoroughly every eight hours. On the 20th there was no alteration in the patient's condition. His temperature was $100^{\circ}$ and his pulse-rate was 74. On the 21st he took notice of his surroundings to some extent. Iced milk and soda water were given and retained. On the 22nd he was much improved; he had taken more notice and had spoken. On the 23 rd the improvement was continued and from this time he progressed slowly, gaining in strength and weight; his general condition is also returning to what it was previously to the illness. The use of the ointment was continued for about two weeks.

Two years ago the patient's brother, eight years of age (whom in appearance the parents inform me he greatly resembles), was attacked with precisely the same symptoms and died after an illness of six or seven days; his case was diagnosed by a consultant and the medical man in attendance as tuberculous meningitis. I understand that there is on the 